\title{
UNDERSTANDING TYPE, PROCESS AND ELEMENTS OF CHANGE: A CONCEPTUAL REVIEW ON THE FRAMEWORK OF CHANGE MANAGEMENT
}

\author{
Ratana SOM ${ }^{a^{*}}$, Raksmey CHAN ${ }^{b}$, Dănuț DUMITRAȘCU \\ ${ }^{a}{ }^{b}$ Royal University of Phnom Penh, Cambodia \\ ${ }^{c}$ Lucian Blaga University of Sibiu, Romania
}

DOI: $10.24818 / \mathrm{IMC} / 2020 / 03.01$

\begin{abstract}
Struggle to deal with change is not a current phenomenon. In 1950s, Kurt Lewin projected a scientific top-down and planned approach to manage change. Some 40 years later, emergent approach of Kotter, Kanter, Stein, Jick etc. came in to challenge earlier take, stating that change cannot be managed by top-down planning. Contemporary theorists, including Orlikowski, Yates, Willmott, Bridgman, Wagner, Newell etc., had nothing to deny those takes, but adding in another management aspect of change, known by some as elements of change. Despite some back-and-forth criticism, we found those theories, including the earlier ones, are still relevant in today's context. We argue, therefore, that the real issue is not their irrelevancy, but their ambiguity. By comparing and contrasting relevant literatures, this digest aims at seriously understanding each of these theories, making sense of their strengths and weaknesses, and ultimately drawing up their real constructs for practical application. We conclude that, to deal with change, one has to factor in both-the broader managerial aspects of change, which include type, process and elements, and their respective inside indicators, so that all are inclusive and measurable.
\end{abstract}

KEYWORDS: change framework, change management, elements of change, type, process

\section{INTRODUCTION}

Change methodology has shifted from time to time. Originating from Kurt Lewin's planned approach that dictates a top-down strategy to manage change (Burnes, 2004; Lewin, 1951), later studies during the 80s and 90s brought in more complexity (Kanter et al., 1992; Kotter, 1996), supposedly a consequence of the fast-paced development of technology and globalization. These 'emergent' approaches focused largely on process building to mitigate changes which are fast and unpredictable, while also contradicting Lewin's take on the fact that effective change is bottomed up, and driven by middle-managers who are directly facing the changes on the ground (Bamford \& Forrester, 2003). To these later theories, change cannot be planned, and hence the role of top managers is not that critical. Without specific objection to any of the earlier thoughts, the contemporary theories have, however, viewed success of change as just mere consequence of a symbiotic relationship among change elements - the human, technology and strategy (Orlikowski \& Barley, 2001; Orlikowski \& Yates, 2006; Smuts et al., 2017). To these very theories, successful change depends largely on how well these three elements work together.

Regardless of being supportive, or contradicting to one another, these theories are agreeing on a number of important aspects. First, the management of change requires a clear understanding of type (finetuning, incremental, transformational etc.); second, managing change must undergo a specific change process (top-down, bottom-up or even a mix), and last, a successful change requires

\footnotetext{
${ }^{*}$ Corresponding autor. E-mail address: sr.ratanasom@yahoo.com
} 
the employment of appropriate change elements (human, technology, strategy) (Bamford \& Forrester, 2003; By, 2005).

Despite the agreement, the aforementioned aspects are still seen to be broad for real application. It is therefore the aim of this paper to look in-depth into those aspects to further determine their detail constructs with hope that the findings could further inform this generation researchers of a more scientific approach to manage change.

For better understanding, this paper is structured thematically, devoting its first part to the discussion of 'change type', moving on to 'change process' and ending by a detail discussion of the 'elements of change', which includes, human, technology and strategy elements. As other papers do, a general conclusion is drawn to sum up the whole paper.

\section{TYPE OF CHANGE}

To plan a change project, one must decide on type. Choosing an appropriate type will give change managers not just the ideas of size and scale of a project to be changed, but a complete sense of resources to be mobilized for the change project. At one time, organizational change is small, and hence requires just a small tactical finetuning; yet, at other time, change could assume a much bigger scale, known by many as a departmental change, or even modular transformation. At worst, change may also take a form of a complete transformation shall an organization experiences real turbulence.

By (2005) categorized organizational change into 3 types - change based on the rate of occurrence, change based on how it comes about and change based on scale. To the author, the rate of change varies from continuous, discontinuous, and incremental. While Luecke (2003) term continuous and incremental change in the same package, Burnes (2004) explained that unlike incremental change, which takes place as an organization, continuous change is described as departmental change. "Continuous incremental change, for Luecke (2003), is known as a change made through a series of small but more frequent improvements". As for discontinuous change, Grundy (1993) refers it to "change, which is marked by rapid shifts in strategy, structure or culture, or in all three". Luecke (2003) called discontinuous change as "single, abrupt shift from the past" and taking in the one-time event and large. He added, "Discontinuous change takes place through major, widely separated initiatives. Performance gains through those steps are followed by long periods of consolidation and quiescence" (Luecke, 2003).

Change based on how it comes about is divided into two-planned and emergent change. According to Lewin (1951), the effective change required detailed plans and projection made by top managers. Change had to start from a clear objective supported by detailed planned actions, and with projectable results. Change was attainable through the process of freezing, unfreezing and refreezing, or termed differently as displacing, reregulating and rearranging (Heifetz et al., 2009; Lewin, 1951). Bamford and Forrester (2003), however, challenged the concept casting doubt mainly on the role of top managers. A good change management had to be a bottom-up, and crosssectional. Changes took place variedly and immediately at functional offices governing by functional managers. Senior managers might dictate general policies, but it was the middle managers who were directly "influenced" by events, who liaised with important customer contacts and spent time with both internal and external auditors (Bamford \& Forrester, 2003). This latter type is noted as emergent change. 
Change based on scale could be separated as fine-tuning, incremental adjustment, modular transformation, and corporate transformation (Dunphy \& Stace, 1993). Fine-tuning, a type of organizational change, is described as the changes in an organization's strategy, structure, people, or processes with small impacts. The author explained further on incremental adjustment that this change is not radical, yet the organizational strategies and working processes are modified. If the change goes more severe and happens in one or more departments, the change is considered as modular transformation. In addition, some changes may take place as a whole organization, cooperating from one department to another and radical in altering organizational strategies, this is called as corporate transformation (Dunphy \& Stace, 1993) .

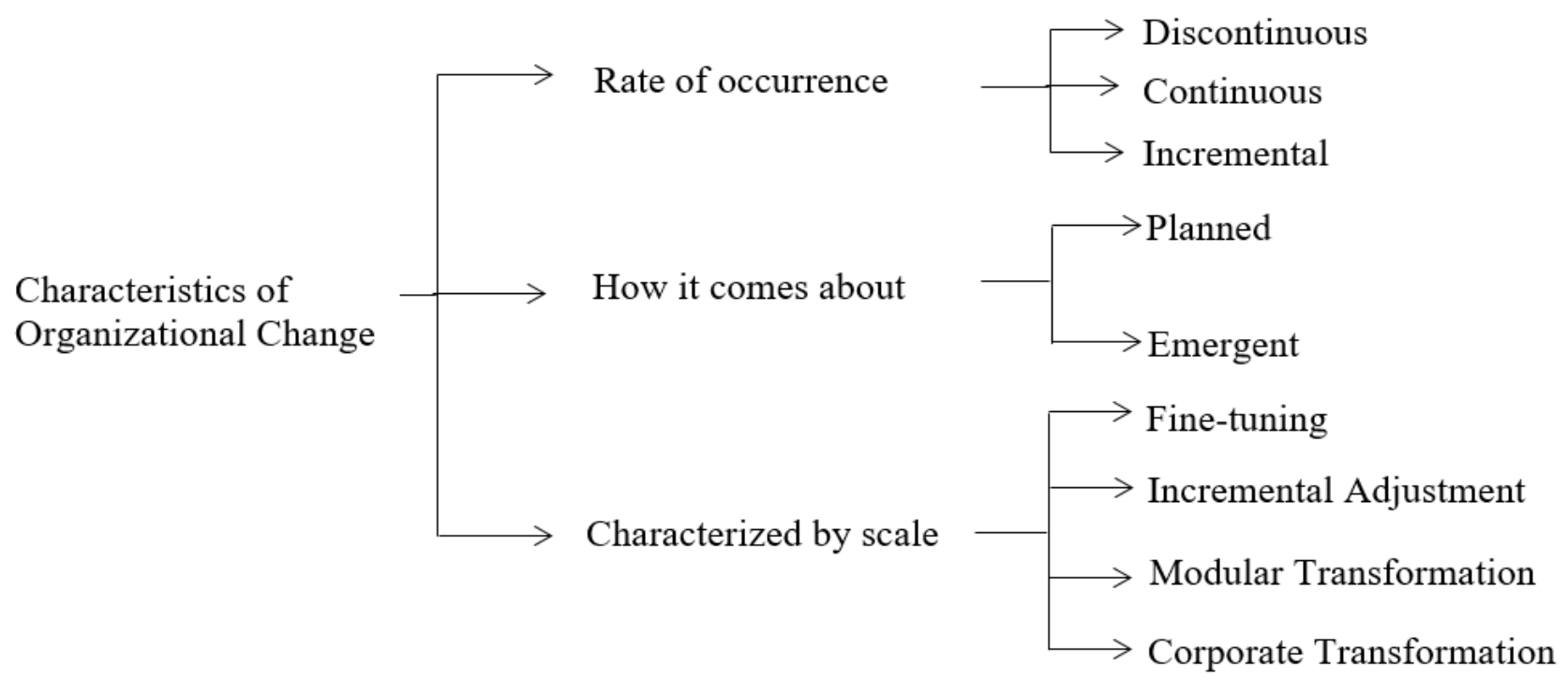

Figure 1. Characteristics of Organizational Change

Source: adapted from By (2005); Dunphy and Stace (1993)

The above characteristics suggest that change appears in many different forms each of which has the impact on the management of change. A clear understanding of which type to choose for a change project is of real asset for change agent as that may impact not only the choice of process, but also the effective functioning of relevant change elements that help ensure the overall success of the change project.

\section{PROCESS OF CHANGE}

Change process has long been discussed since the onset of the change management discourse. In the 50s, Kurt Lewin famously introduced his planned change process wherein he stressed the top-down approach for the management of change. The theory dictates a 3-step process of unfreezing the old habits, moving and acting with new practices, and refreezing the practices into a new routine. Change, according to the theory, has to be planned by top managers who have all the authorities down the line of execution. Despite its historic success, Lewin's top-down approach has later been heavily criticized for its inapplicability for the contemporary change context, which is fast and less predictable. On the critique list is the note that the theory presents so broad a process that allows not many managers, particularly the inexperienced ones, to properly execute the change effectively. The three-step guideline, to be precise, is seen to be too loose, and offering too much flexibility to top managers to execute the change. The broadness has weakened not only the change process itself, but also contradicted the nature of 'planning' as suggested by the theory per se. 
As planned change becomes less applicable for the new context of organizational change, emergent group of change theories, presented by a number of authors (Burnes, 2004; Kanter et al., 1992; Kotter, 1996), reveals their merits. Some of the very theorists who took the side include Kotter (1996), who proposed 8-step of change, providing clear insight for the managers to follow; Kanter et al. (1992) who offered the ten commandments for executing change; and Luecke (2003) who devised the 7-step to change approach. To these theorists, change takes place so sudden, and is triggered by both external and internal factors, which do not allow top managers to do appropriate pre-planning. A successful change is therefore not relying on a good planning but on the readiness for flexibilities on the ground when change occurred.

Despite gaining ground for a period of time, emergent change projects its limitation as well. This bottom-up approach is surrounded by criticism on its rigid steps to change, requiring too complicated procedures for managers to implement, which is in many ways unachievable. Considering Kotter's eight-step model, for instance, managers are commanded to follow all the steps, and if skipping any one of it will result in failure (Appelbaum et al., 2012). The author further noted that, in spite of some concrete practicalities, the emergent approach is neither at all times applicable, especially when the change is small and simple, nor favorable for many experienced managers who needed broader liberty to manage change in their own style.

To put things into a broader perspective, the above approaches present both challenges and opportunities. While the main challenge sticks to the fact that none of the above schools of thought could be a stand-alone doctrine, they are still indeed making their own merits. The planed change, known by its top-down management process, for instance, despite being subsequently challenged, is still working well in the contexts of developing countries and of those newly emerging democracies where concrete planning, developed by top managers, are still relevant. On this point, caution shall however be made on the fact that 'planning' shall not be necessarily meant a dictation of the whole change process which is supposed to be continuous and open-ended. To the most the so-called 'planning' could do is setting a path with some clear milestones (setting a vision with achievable objectives), and yet leaving the room for flexibility to those on the ground to deal with sudden changes. Such flexibility is indeed the core essence of the bottom-up process presented therein the emergent theories.

While sticking to any side of the contrasting continuum could be a mistake, a tendency therefore to look at any existing theory that stands in-between becomes more obvious. With neither loose process, nor many rigid steps to change, Judson's five-phase process gains concrete momentum. Developed from Lewin's 3-step approach to change, this process holds a blended nature between the planned and emergent approach to change. The process is not fixed and limited to planned steps that managers have to develop to deal with small scale of change, but rather it provides insight for the implementer to be flexible to fit with the new nature of change that seems more likely to be emergent. Judson (1991) processes to change contains merely five-step which include (1) analyze plan the change (2) communicating the change (3) gaining acceptance of new behavior (4) changing from a status quo to a desired state and (5) consolidating and institutionalizing the new state.

To sum up, Lewin's top-down process, despite gaining ground even until recently, is seen to be loose in the management sense as it fails to present concrete details for managers to follow. The emergent approaches, in spite of taking note of the intricateness of change, are otherwise producing unnecessary complexities due to their rigid bottom-up process. A theory that is therefore worth noting for contemporary change managers is supposedly Judson's 5-step to change which is outlasted other approaches as its rigorous and simple steps have clearly defined the current practice of change management. 


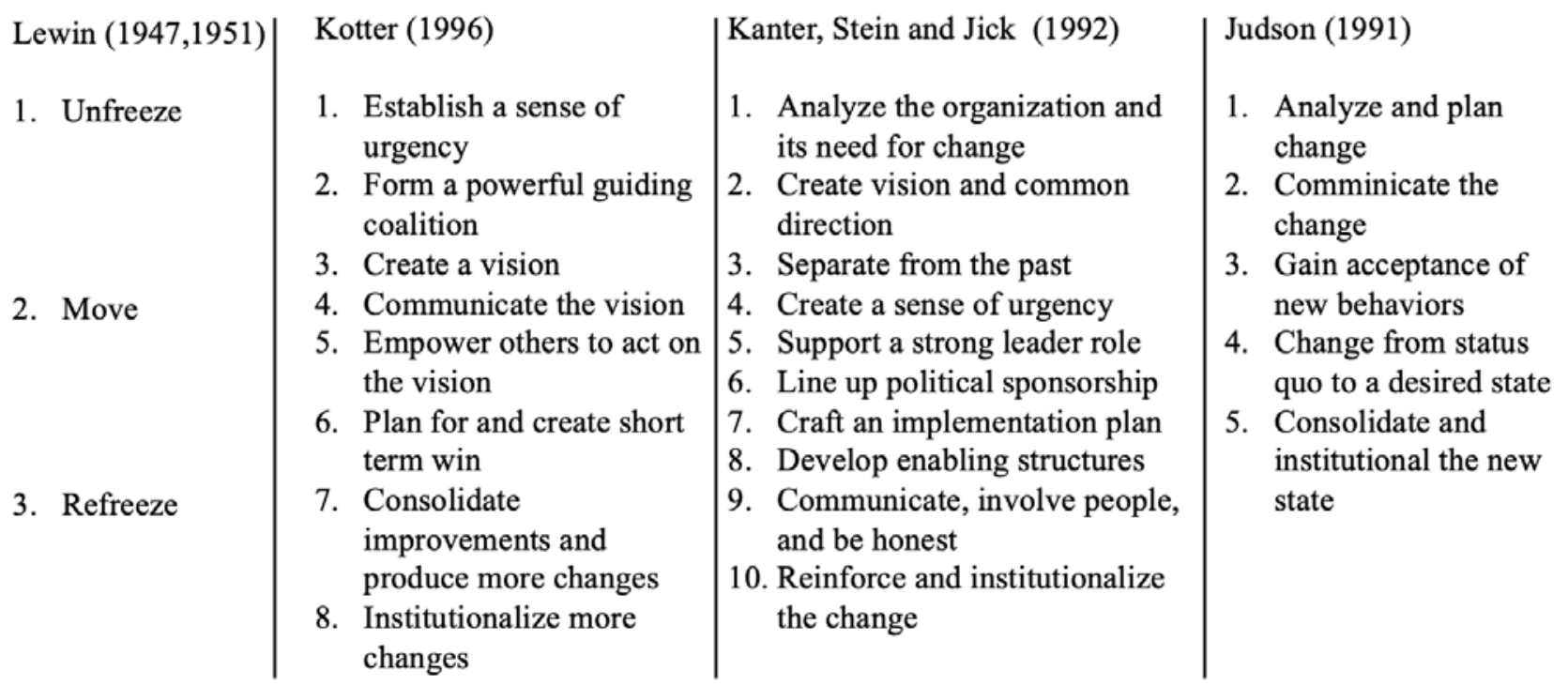

Figure 2. Change Management Model/ Process

Source: adapted from Judson (1991); Kanter et al. (1992); Kotter (1996); Lewin (1951)

\section{ELEMENTS OF CHANGE}

Considering pre-1990s theories, the discussions of managing change were more centering on human role and strategy. It was the role of the top managers versus the ground managers, and it was about the top-down or/and a bottom-up strategy. Coming to the 1990s, the debates were on step buildings. The overwhelming discussion of step during this period was seen to be of a real reaction to change, which is vast, fast and unpredictable due to the influence of technology. This later element, together with the previous ones-human and strategy-are becoming the core substances of the contemporary theories which bet the success of change on a smooth relationship among the three elements-human, technology and strategy.

The discourse of the symbiotic relationship among the above elements in the change process was reflected in the work of Wagner and Newell (2006) who pointed to the criticality of these three elements in the management of change. In that same year, Orlikowski and Yates (2006) also pointed to the constructs, yet coining them as "making system workable, dealing with materiality, and focusing on practice". To these authors, the first term refers to a strategy that focuses on setting common goals for all change stakeholders in the institution. "Dealing with materiality" touches mainly on the ability to see technology as more than just tools; a notion shared by Bridgman and Willmott (2006), and "focusing on practice" focuses on what people do with technologies in practice (what actors at various level within and across organizations are doing with the technology on the ground and over time).

Some years later, Anderson and Anderson (2011) confirmed the need for change managers to take simultaneous attention to the same areas when change project is initiated. To these authors, a successful change requires a smooth interaction of content, people and process. Although the term "content" they referred to was largely about "the various elements of change", technology was indeed one of them.

To be understandable, and measurable, human, technology and strategy are discussed as follows.

\subsection{Human Element}

Although many authors have raised 'human' aspect as a crucial tool for change, the exact indicators of which have yet to be identified. Out of the many discourses, a few of the common indicators that 
could be drawn are the working culture, resistance to change, trust, and role and responsibilities (Kotter, 1996; Luecke, 2003; Reynolds, 1994).

Since early time, 'human' element is found to be deeply embedded in the working culture of an institution. Higher Education Institutions (HEI), for instance, is known to be embracing the academic culture possessed mainly by their academic staff (Davies et al., 2007). Kezar and Eckel (2002) have identified institutional culture as collegial, managerial, developmental and negotiating, noting that some are more open for change, while others not. A need to understand culture type and its embedded human sentiment before any initiation of a change project has therefore become a fundamental prerequisite for change success.

Resistance to change is another indicator in human element. While change could be either good or bad, caution should always be raised on how to mitigate the latter. One of the many ways is the development of strategy to deal with forces of resistance which could stem from the unwelcomed culture. Kotter (1996), and Anderson and Anderson (2011) emphasize the need to deal with such resistance by advising change manager to be always on alert of cultural differences once change project is initiated. Meanwhile, Kotter (1996), together with Alas and Vadi (2006) have also cautioned of the other root causes of resistance which are not directly stemming from culture. These include the loss of trust and possession, misunderstanding and the lack of capacity.

Another indicator of human element is roles and responsibilities. Normally, a new change project comes with new tasks embedded in the assigned roles and responsibilities. A change would require an explicit redivision of workload, realignment of workflow, and a clear set of new responsibilities among implementers. Without that, change would create a chaotic situation in which people are uncertain about their new role and responsibility. At one point in time, a change spectrum could be more than just a realignment of roles and responsibilities, and it, at other time, requires additional trainings for staff to accommodate themselves in the new environment. China, for example, in an effort to shift its traditional teaching and learning practices to a new online platform, obliged all staff, no matter how great they are in pedagogical skills, to undergo training for the proper use of technology (Gu, 2016). Such training need had long been noted by theorists, including HewittTaylor (2003), as an important aspect to be factored in for any new change project, particularly for changes on part of technology (Birchall \& Giambona, 2008; Marchesoni et al., 2016). Without sufficient support on this, change will be not be successful.

Drives to understand human element is seen to be more and more crucial for studying change, especially in the current context although challenges in making clear sense of it is still obvious. Indicators, including leadership skills, support, adaptive design, to name a few, are raised in some literatures but they are viewed as more of tactical strategy than that of the contextual elements which are limited in this study only to culture, resistance to change as a result of losing trust, and/or possession, and roles and responsibilities.

\subsection{Technology Elements}

Many authors have proved the relationship between human and technology in the management of change. Orlikowski and Yates (2006), for example, stated that technology, namely the ICT, was both a concrete artifact and an actor that influenced and was influenced by the cognition and actions of its users. Andersen (2018) also acknowledged the reciprocal relationship between ICT users and organizational change that increased autonomy and control power of organizational norms and routine could be made by ICT. Despite the proven relationship, the term technology is still ambiguous to comprehend, particularly on its exact roles in organizational reform.

Literally, technologies in this study refer partly to tools-products of new innovations. According to Zuppo (2012), technology could be a close acronym of ICT that covers devices such as phones, tablets, pagers and other wireless tools. Other studies bluntly refer technology to communication technologies and websites, covering instant messaging, voice over IP (VoIP), video-conferencing and social media platforms such as Facebook (Christensson, 2010). In the field of education, the 
availability of technology as tools including MOOC, Google classroom, and Learning Management System (LMS) have revolutionized the ways things are taught and learnt, making a new online platform possible for distance education.

In line with earlier calls to look at technology beyond its material status (Markus \& Robey, 1988; Williams \& Edge, 1996), later studies are viewing technology as the ability to use technological tools. Zuppo (2012), for example, referred technology to the competency and skills in using the tools for teaching and learning. Orlikowski and Yates (2006) coined 'dealing with materiality' just to refer to human ability to use technological tools and devices. Their rational is based on the fact that once technological tools were introduced in a change project, it requires additional training for staff to operate the tools appropriately. Inadequate support and training is proven to be one of the primary causes of resistance to change which after all leads to a complete failure of change project (Khan et al., 2012).

More than just tools and the ability to use them, technology in many occasions is referred to a 'system'. Generally, once a change of technology is proposed in an institution to deal with a drive for change, such change needs other technologies to support the adjustment. The support could be in form of employing technology, not just a tool, but as a system for communication, data sharing, or even troubleshooting. This instance is particularly essential when the size of change is vast and fast, and is uncontrollable by the old school of practices. The move to embrace LMS for Blended Learning (BL) in education, for example, encounters many issues related to training, and quality management (Tshabalala et al., 2014). In dealing with that, change team could possibly embrace other technologies such as instant messaging or other data management software to facilitate the integration of the adoption. At other instance, a change of technology as an element is, however, needed to improve the productivity or efficiency of the work ecosystem. The move to adopt LMS in education was, for instance, effective for learners and educators in the modern context, but this inevitably requires the improvement of the existing ICT infrastructure such as internet bandwidth, speed, connectivity, technological support and maintenance, without any one of them, the change is not complete and successful.

A conclusion could thus be drawn that technology and organizational change are reciprocally interrelated. When we talk about technology integration into the workplace, one must not avoid discussion on changes needed for successful integration. Likewise, when one talks about change, one must also not forget to consider technology, which must be seen more than just tools, but skills to use the tools and system to support them. Short-term results would be achieved, while increasing instability instead of reducing it, if there was a one-side intervention on any of these two variables-technology and change (Genus, 1998; Hartley et al., 1997; Som \& Dumitrascu, 2019).

\subsection{Strategy Element}

In managing change, the discussion of strategy is easier understood when having it discussed alongside with process. While the latter is more rigid and general, the earlier is more specific, and yet highly flexible. The power of that flexibility makes strategy as 'an essential tool' to ensure a stage-to-stage success of the whole change process. Strategies vary in names, and bending to time and context of which they are being applied. They present themselves in the forms of direct communication, message redundancy, face-to-face communication, management external information, persuasive communication, and active participation (Armenakis \& Bedeian, 1999; Klein, 1996).

It is commonsense that once a change aspect identified and that a change project is initiated, communicating the change is next on the list. Towards this same objective, different theorists might have used different tactics and strategies that fit both time and context within which change is being made. Klein (1996), for example, points out a few mechanisms, which include repetition, face-toface communication, and soliciting useful information to communicate the change. To Klein, making employees believe and realize the compulsory of change needs repetition. Repeating 
strategy could take the forms of writing, pronouncement, or/and discussion that could all ensure the change initiative reaches the intended target. In addition, face-to-face communication could also be an effective strategy of communicating change as it could hardly leave room for misleading interpretation. Such direct discourse allows change managers to present not only the change initiative to relevant employees with clarity, but also a platform to receive instantaneous and useful feedbacks from those employees. To further attract them to the change idea, managers should be able to illicit only important information to communicate to those employees as they may choose to hear more personal and relevant information than those abstract and general ones (Klein, 1996).

Armenakis et al. (1993) claimed, in order to influence and make employees ready to listen to change initiative, managers must make sure that they have already had some basic knowledge of the change from various external information. Managers can, in this regard, trigger the urge for change by spreading the current difficult situation of the institution, including some change-related information, on radio, television, broadcast, or magazine. With all those in place, persuasive communication and active participation (reflected in repetitive presentation, personal speech, telephone conferences, newsletters, or annual reports) could then be used to magnify the urgency for change among those workers.

In sum, change project could never be accomplished without good strategies. While process guides the path, strategies guide the step. The overall success of a big project requires the right path, and the combined successful steps.

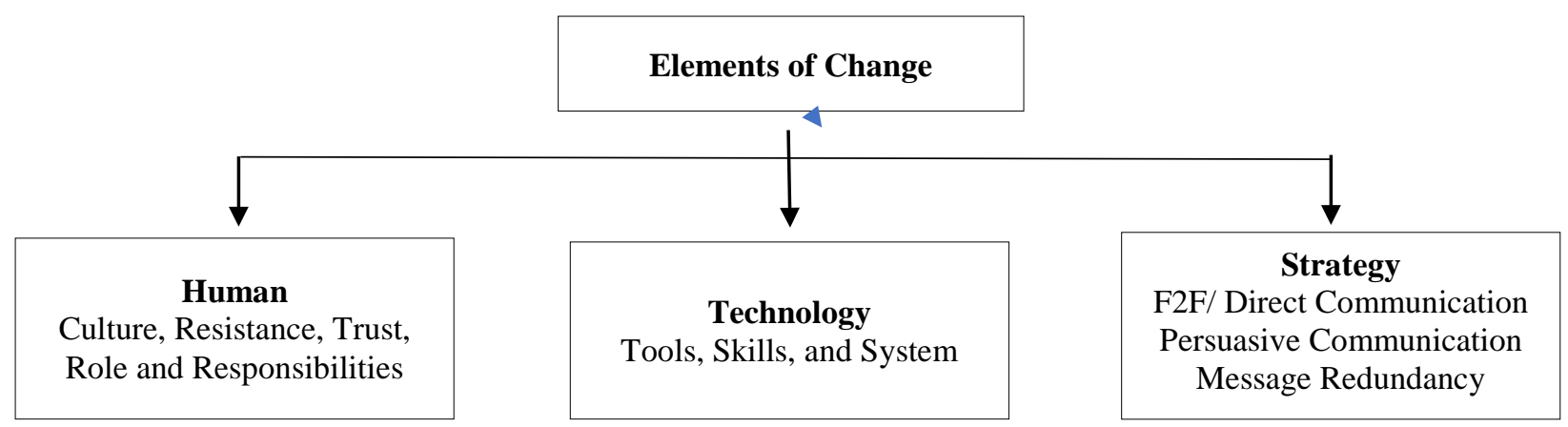

Figure 3. Elements of Change

Source: Authors

\section{CONCLUSION}

In conclusion, managers, to execute change successfully, must anticipate the exact type of change in the first place. This would be a consideration of if the change is in a form of corporate transformation, a small fine-tuning, continuous or discontinuous, planned or emergent, etc. Next, they should analyze the steps through which the change is led. This is all about identifying what should be done first and second. While preparing steps to walk, managers have to consider change elements which include, human, technology and strategy, checking what should be done to deal with human aspects (the resistance to new working culture etc.); the kind of technology to be used in the change project (would this technological reform require the change as a system, and do the staff know how to operate it? etc.) Meanwhile, effective strategies are also needed not only to deal with change elements but to fulfill the planned steps that have been anticipated earlier. They need to make sure that all of them are working well together. Underestimating any of these constructs would make the change project a complete failure. 


\section{REFERENCES}

Andersen, T. K. (2018). Understanding the success or failure of organizational ICT integration: The criticality of managerial involvement. Journal of Change Management, 18(4), 327-343.

Anderson, D. \& Anderson, L. A. (2011). Conscious change leadership: Achieving breakthrough results. Leader to leader, 2011(62), 51-59.

Appelbaum, S. H., Habashy, S., Malo, J.- L. \& Shafiq, H. (2012). Back to the future: revisiting Kotter's 1996 change model. Journal of Management Development, 31(8), 764-782.

Armenakis, A. A. \& Bedeian, A. G. (1999). Organizational change: A review of theory and research in the 1990s. Journal of Management, 25(3), 293-315.

Armenakis, A. A., Harris, S. G. \& Mossholder, K. W. (1993). Creating readiness for organizational change. Human Relations, 46(6), 681-703.

Bamford, D. R. \& Forrester, P. L. (2003). Managing planned and emergent change within an operations management environment. International Journal of Operations \& Production Management, 23(5), 546-564.

Birchall, D. W. \& Giambona, G. (2008). The impact of ICT on the work patterns of managers and their organisations. EuroMed Journal of Business, 3(3), 244-262.

Bridgman, T. \& Willmott, H. (2006). Institutions and technology: Frameworks for understanding organizational change-The case of a major ICT outsourcing contract. The Journal of Applied Behavioral Science, 42(1), 110-126.

Burnes, B. (2004). Kurt Lewin and the planned approach to change: a re-appraisal. Journal of Management Studies, 41(6), 977-1002.

By, R. T. (2005). Organisational change management: A critical review. Journal of Change Management, 5(4), 369-380.

Christensson, P. (2010). ICT Definition. Retrieved September 11, 2020, from https://techterms.com/definition/ict

Davies, J., Douglas, A. \& Douglas, J. (2007). The effect of academic culture on the implementation of the EFQM Excellence Model in UK universities. Quality Assurance in Education, 15(4), 382-401.

Dunphy, D. \& Stace, D. (1993). The strategic management of corporate change. Human Relations, 46(8), 905-920.

Genus, A. (1998). The management of change: perspectives and practice. London, UK: International Thompson Business Press

Grundy, T. (1993). Managing Strategic Change. London, UK: Kogan Page

Gu, X. (2016). Blended Learning at East China Normal University: Promising Practices and Challenges. In C. P. Lim \& L. Wang (Eds.), Blended Learning for Quality Higher Education: Selected Case Studies on Implementation from Asia-Pacific (pp. 39-66). Paris, France: United Nations Educational, Scientific and Cultural Organization.

Hartley, J., Benington, J. \& Binns, P. (1997). Researching the roles of internal-change agents in the management of organizational change. British Journal of Management, 8(1), 61-73.

Heifetz, R., Grashow, A. \& Linsky, M. (2009). The Practice of Adaptive Leadership: Tools and Tactics for Changing Your Organization and the World. Boston, MA: Harvard Business Press.

Judson, A. S. (1991). Changing behavior in organizations: minimizing resistance to change. Cambridge, Mass.; Oxford: Blackwell Business.

Kanter, R. M., Stein, B. A. \& Jick, T. D. (1992). The challenges of execution: roles and tasks in the change process. The Challenge of Organizational Change, 369-394.

Khan, M. S. H., Hasan, M. \& Clement, C. K. (2012). Barriers to the introduction of ICT into education in developing countries: The example of Bangladesh. International Journal of Instruction, 5(2), 61-80. 
Klein, S. M. (1996). A management communication strategy for change. Journal of Organizational Change Management, 9(2), 32-46.

Kotter, J. P. (1996). Leading Change. USA: Harvard Business School Press.

Lewin, K. (1951). Field theory in social science. New York, NY: Harper.

Luecke, R. (2003). Managing Change and Transition. USA: Harvard Business School Press.

Marchesoni, M. A., Axelsson, K., Fältholm, Y. \& Lindberg, I. (2016). Going from "paper and pen” to ICT systems: Perspectives on managing the change process. Informatics for Health and Social Care, 42(2), 109-121.

Markus, M. L. \& Robey, D. (1988). Information technology and organizational change: causal structure in theory and research. Management Science, 34(5), 583-598.

Orlikowski, W. J. \& Barley, S. R. (2001). Technology and institutions: What can research on information technology and research on organizations learn from each other?. MIS Quarterly, 25(2), 145-165.

Orlikowski, W. J. \& Yates, J. (2006). ICT and organizational change: a commentary. The Journal of Applied Behavioral Science, 42(1), 127-134.

Reynolds, L. (1994). Understanding employees’ resistance to change. HR focus, 71(6), 17.

Smuts, R. G., Lalitha, V. M. \& Khan, H. U. (2017). Change management guidelines that address barriers to technology adoption in an HEI context. Paper presented at the IEEE 7th International Advance Computing Conference (IACC). Hyderabad, India.

Som, R. \& Dumitrașcu, D. (2019). A Critical Reflection on Relationship between ICT and Change Management in Enhancing Teaching and Learning Performances. Paper presented at the 9th Balkan Region Conference on Engineering and Business Education and the 12th International Conference on Engineering and Business Education. Sibiu, Romania.

Tshabalala, M., Ndeya-Ndereya, C. \& Merwe, T. v. d. (2014). Implementing Blended Learning at a Developing University: Obstacles in the Way. Electronic Journal of e-Learning, 12(1), 101110.

Wagner, E. L. \& Newell, S. (2006). Repairing ERP: Producing social order to create a working information system. The Journal of Applied Behavioral Science, 42(1), 40-57.

Williams, R. \& Edge, D. (1996). The social shaping of technology. Research Policy, 25(6), 865899. 